\title{
The relationship between Product Innovative Strategies and Performance of Kenya Tea Development Agency Factories in Kenya
}

\author{
Koech Chepngetich Dorothy ${ }^{1}$, Langat Lydia, Phd $^{2}$, Bett Alfred, Phd ${ }^{3}$ \\ University of Kabianga, Kericho- Kenya
}

\begin{abstract}
Kenya Tea Development Agency's primary role is to collect plucked tea, process and market tea products on behalf of farmers. Despite the crucial role it plays in Kenya's economy, the tea sector still faces various challenges such as high cost of production, fluctuations in the international market, and emerging issues such as COVID-19 pandemic. To effectively improve the performance of the tea industry, product innovative strategy practices are widely acknowledged for improving productivity and competitiveness in the sector. This study aimed at establishing the relationship between product innovative strategies and performance of KTDA factories in Kenya. It was premised on Schumpeterian theory of innovation and Discovery theory. A correlational and cross-sectional research design was adopted in this study. The target population was 974 employees from 71 KTDA factories in Kenya. A sample of 283 respondents was drawn from four regions using a stratified sampling method. The main instrument of data collection was a semi-structured questionnaire administered to top, middle, and lower-level employees of KTDA factories in Kenya. The questionnaire was pre-tested to ensure its validity and reliability. An aggregate Cronbach Alpha coefficient of 0.703 was obtained. Multiple linear regression and model was employed to determine the significance of the hypothesis. The findings revealed that product innovative strategies $(\beta=$ $0.695, \mathrm{R}=0.748, \mathrm{p}<0.05$ ) had a positive and significant relationship with performance of KTDA. The study recommends that stakeholders and interested parties in the industry should make policies that goes toward operationalizing product innovative strategies. The findings may be useful to the industry stakeholders in formulating product innovative strategies that will help improve their fortunes.
\end{abstract}

Key Words: Product Innovative Strategies, Organization Performance, Tea Industry

\section{Introduction}

Globalization brings opportunities as well as pressures for domestic firms in emerging markets forcing them to use product innovative strategies to improve their competitive position. According to Thomas, Narayanan and Ramathan (2012), amidst globalization and stiff international competition, innovative strategies are pillars for survival and sustainable development. Baregheh, Rowley, and Sambrook (2009), argue that firms are forced to apply innovative strategies to meet consumer needs and wants which are rapidly changing. To take advantage of opportunities and meet consumer needs firms have had to use innovative strategies in their processes, products, markets and management.

Emerging issues like COVID-19 pandemic, globalization, changes in customers tastes and preferences among others have had far reaching effects and unprecedented change on the performance of organizations (Wong, Ho, Cheung and Yeoh, 2020).The exportation of tea, coffee, fresh produce and cut flowers in East Africa have been greatly negatively affected by COVID-19 containment measures such as closing down of auctions and mass gatherings which have led to disruptions in the supply chains (Morton, 2020).

Innovative strategies refer to a plan adopted by an organization to encourage advancements in technology or service to enhance its competitive advantage in the market (OECD, 2005). Product innovative strategies can be termed as strategies where a good or service is enhanced in terms of its elements and how it is to be used, it includes technological improvements in specifications of components and material and software that have 
been incorporated which may make the goods or service better in terms of how they are used and how they function generally. It can make use of technological advancements or knowledge or new found uses of a good or service or a combination of both existing technology and knowledge ( Oke, Prajogo and Jayara 2013),

Oke, Prajogo and Jayara (2013), pointed out that product innovative strategies improve the characteristics of goods and services which is also associated with a new product. Technology's role in transformation of a product is very important. According to Oke, Prajogo and Jayara (2013), product innovative strategies involve improvement of the quality of a product which has positive significant influence on firms' performance. Augusto, Lisboa and Yasin (2014), noted that from the different types of innovative strategies, product innovative strategies affects organizations performance greatly. This was also pointed out by Ar and Baki (2011), who noted that the relationship between product innovative strategies and organizations performance is strong and positive.

There is need also to consider customer needs while developing a new product to ensure that product innovative strategies taken are efficient and effective (Polder, Leeuwen, Mohnen and Raymon, 2010). High creativity was identified as an important element in product innovative strategies as it aids in product quality improvement, according to Onikoyi (2017), this would ensure high performance.

In studies conducted, financial gain has been identified as a major benefit to be derived from implementation of product innovative strategies (Cozza, Malerba, Mancusi, Perani and Vezzulli, 2012). HernandezEspallardo and Ballester (2009), also got the same results from research which was that, product innovative strategies had a positive influence on performance of organization. There are quite a number of studies that have been conducted in Kenya to show the relationship between product innovative strategies and organization performance such as Karanja (2014), conducted a study on innovative strategies and their influence on the competitive advantage. Letangule and Letting (2012), also conducted a research on innovative strategies in the telecommunication industry and found that the main innovative strategy that affected the industry was product innovative strategies which influenced the profitability of the organization greatly.

Product innovative strategies have been shown to play a crucial role in securing sustained competitive advantage. Therefore, organizational theorists and managers alike have long shown more interest in the role of product innovative strategies in organizations. As organizations attempt to gain competitive advantage, they develop and/or adopt new products. This study aimed to bridge the existing gap in the literature by reviewing the product innovative strategies adopted by KTDA factories in Kenya. The aim of this study therefore is to investigate the relationship between product innovative strategies and performance of KTDA factories in Kenya.

Production cost reduction, value addition to products towards achieving maximum customer satisfaction and high returns on investment clearly define tea factories performance. They include market share, product quality and company image among others.

\section{Kenya Tea Development Authority in Kenya}

In Kenya Tea companies are directly linked with KTDA holdings which includes KTDA Power Company for generation of hydropower generators, Chai trading company for storage, Majani Insurance for insurance and brokerage, Greenland Fedha for micro finance service, KTDA MS for tea cultivation, payment, processing and marketing and Kenya Tea Packers for tea blending and packaging. This inclusive model ensure that farmers are well trained, access finance, payment for tea plucked and access bonus. KTDA has financed the construction of new warehouses to handle storage and improve supply chain. These integration of innovation ensure high production, quality tea product and low cost of production (International Finance Corporation, 2013). KTDA have ensured innovation through technological advancement and research, marketing and publicity, ICT integration, improvement of green leaf quality and tea products (Christian Partners Development Agency, 2008). Also, majority of innovative strategies are adopted, implemented and utilized at factory level to ensure that the tea produced is within the required quality, standards and fetch the best prince. Despite, high diffusion of innovation in manufacturing sector, KTDA factories receives different shares of profits that are normally converted to bonus from across different KTDA factories. 
The small holder sector factories are managed by Kenya Tea Development Agency (KTDA). In an effort to meet customers' demands and at the same time make profits tea processing organizations encounter many obstacles. Some of the challenges as highlighted by Abeysinghe (2013), include but are not limited to demand for higher pay by staff which is a major attribute to a high cost component, the cost of inputs is also high such as the costs used in fuel, costs of machinery and other costs associated to the agrochemicals; lately there has also been a drop in production levels in all processing factories, farmers are also shying away from planting new tea bushes thus there is mostly aging tea bushes and increase in large uneconomical tea lands; there is also a shortage of unskilled labor; global warming has caused a change in weather patterns; tea processing requires a lot of energy which has been hard to meet; there are many requirement for safety of food; many certificates have to be acquired and also several protocols to be fulfilled in hygiene for tea processing; the factories have to ensure workers safety requirements are adhered to; so as to be able to increase their share in local and international markets. KTDA as an organization are continuously implementing innovative strategies and this is again scaled down to the different subsidiaries and factories.

\section{Problem Statement}

Tea sector in Kenya contributes significantly to the economy (GDP, employment, foreign exchange through export etc), however it still faces various challenges from low international prices, high tea field costs, competition, souring manufacturing costs, distribution cost and the effect of COVID-19 pandemic. Extant literature indicates that organizations that have adopted product innovative strategies are able to execute their duties better, reduce the cost of operation and are guaranteed survival. While a number of studies have been done in the tea industry there is little demonstration on the relationship between product innovative strategies and performance of KTDA factories in Kenya. Further, empirical literature reviewed indicates that product innovative strategies can improve the performance of organizations through improvements in cost cutting, products quality and quantity among others. However little is has been presented regarding the relationship between product innovative strategies and performance of KTDA factories in Kenya. This study therefore sought to investigate the relationship between product innovative strategies and performance of KTDA factories in Kenya.

\section{Objectives of the Study}

To establish the relationship between product innovative strategies and performance of Kenya Tea Development Agency Factories in Kenya.

\section{Literature Review}

According to OECD, 2005 product innovative strategies can be termed as use of new of better improved goods and services. The study utilized the following theories in developing its literature having found them to be the most relevant; Schumpeterian theory of innovation and Discovery theory.

Schumpeterian theory of innovation is part of the innovative strategies based models put forward by Joseph Schumpeter a renowned economist of the twentieth century (Schumpeter, 1939).He is believed to be a beginning point for modern growth theory whose basis is innovation and a byproduct of the development process. The explanation put forward by Schumpeter of the process of innovation is the same that keeps being applied in modern day and its internationally driven economy (Carayannis and Ziemnowics, 2007).The theory puts forward a variety of reasons for being the reason that there is continuous change in both markets and economy. The changes in the economy in this case is product innovative strategies.

Schumpeter idea of development in terms of the economy is to apply product innovative strategies which includes the launch of a new product or modification of an already existing product (Schumpeter, 1939). He terms creative destruction as process where organization transformation which is the reason for a shift of an organization economically for example through product innovative strategies. Creative destruction in this theory involves breaking old ways of doing things and creating new mental models which encourages introduction of new products and services (Schumpeter, 1939). This theory supposes that the aim of product innovative strategies is to create new products which gives the organization a competitive edge against competitors. 
Schumpeter argued that firms which apply product innovative strategies are able to get increased profits. Based on Schumpeterian theory, product innovative strategies are the foundation for competitiveness and sustained economic growth.

According to discovery theory when there are market or industry imperfections an opportunity to produce new products or services exists (Barney, 1986 and Kirzner, 1997). In discovery theory, competitive imperfections are assumed to arise from external factors, such as changes in technology, consumer preferences, pandemics or some other attributes of the context within which an industry or market exists (Kirzner, 1997). According to Shane (2003), changes in political, regulatory, technology, social and demography are some of the things that cause disruption in the competitive equilibrium that is present in the industry or market, thereby making new opportunities for creation of new products.

The focus on this external factors create opportunities to produce new products or services which leads to important implications. Shocks that take place such as COVID-19 pandemic that take place causes alterations in an already existing industry or market on how it operates thus leading to a new competitive environment, this could be through change in intent and purpose (Levinthal, 1997). Discovery theory views product innovative strategies as looking to the environment for opportunities to take advantage of to be able to have new products or services.

Product innovative strategies takes place when a good or service which have been greatly enhanced in terms of its elements and how it is to be used, the technological improvements in specifications of its parts and material and the software that might have been incorporated which may make the goods or service better in terms of how they are used and how they function generally (Oslo, 2005). It can make use of technological advancements or knowledge or new found uses of a good or service or a combination of both existing technology and knowledge (Bao, Chen and Zhou, 2012). Most product innovative strategies are driven by customer lifestyles which make customer demands to be different, a necessity to shorten product processes, market competition both locally and internationally this is by no means an easy process. For a product innovative strategy to be successful a strong interaction between organizations and also between suppliers and customers is required (Utterback and Abernathy, 1975).

Moreover, a product innovative strategy characteristic can distinguish a new product from competitive offerings and allow the product to get an exceptional position in the market (Im and Workman 2004). Lastly, product innovative strategy has a positive influence through different instruments on new products thus resulting in increased profits and success of the market (Bao, Chen and Zhou, 2012). Gunday, Ulusoy, Kilic and Alpkan, (2011) measured product innovative strategies by establishing the changes in quality of the product, the changes in prices of manufacturing products, the rate of new products progresses leading to easy usage by the customers. Development of new products with various practical particulars and also development of goods and services with elements and materials which are different from the current products may be termed as product innovative strategies.

Jayaram, Oke and Prajogo, (2013) researched on 207 organization based in Australia and found that the relationship between product innovative strategies and product quality were positive to the way the organization performed. In the same light, Hall (2011) when he investigated product innovative strategy activities and productivity relationship found that there was a standard positive association. In the same case, Augusto, Lisboa and Yasin, (2014) researched on the association between organization performance and the different types of innovative strategies and found that the most important innovative strategies in promoting organization performance in the whole organization was product innovative strategy. In the research they conducted, they used factor and regression analysis to provide insights. To add further, Ar and Baki, (2011) in the research conducted between product innovative strategy and organization they found a strong and positive relationship. In the study, they used data from SME managers in the Turkish Science and Technology Parks (STPs) and used structural equation modelling (SEM) Method.

Polder, Leeuwen, Mohnen and Raymond, (2010) argued that product innovative strategies in organizations leads to efficiency and reflects on the type of strategy that the organization has taken. Due to the current high competitive environment, to survive, organizations have to come up with new strategies aimed at 
fulfilling customers' needs which can be through developing of new strategies. Onikoyi, (2017) study investigated product innovative strategies and organization performance. Information were extracted from quality and control, marketing, sales, research and development and production departments which were involved in product development. A sample of 340 employees were given questionnaires. Regression and correlation analysis were used to test the significance of the hypothesis. The results revealed that product innovative strategies had strong impact on the performance of the organization. This was contributed by creativity in product innovation process resulting to improvement of the quality of the product and performance of the firm. Therefore, recommending that organization should improve on human capital creativity in innovation.

Montero, Pennano and Camilo (2017) reviewed literature to determine why some innovative strategies were more successful than others. Their product innovative strategies were examined on the basis of organization factors, development and process factors, market forces factors and strategic factors. The study used metaanalysis of existing literature and found that efficacy and efficiency were used to measure product innovative performance. The study recommended more multi-dimension investigation be done to establish the level of effect product innovative strategies have on performance.

From the literature above, product innovative strategies are broadly seen as an essential component of competitiveness, products and services within an organization. The following studies focused on product innovative strategies and product quality (Oke, Prajogo and Jayaram, 2013) as well as product innovative strategies and organization performance (Onikoyi, 2017).Most studies on product innovative strategies were from different countries and different sectors. This study was focused in the tea sector in Kenya. Very little has been said and done about establishing the relationship of product innovative strategies in relation to performance of KTDA factories in Kenya.

\section{Conceptual Framework}

In this study the dependent variable is KTDA performance measured by Profitability, Cost Cutting, Customer satisfaction and Products quantity/ quality while Product Innovative strategies is indicated by Design and launch of new products, Product transformation, Product quality improvement and New found uses of good or service as indicated in figure 1 .

\section{Independent Variable}

\section{Dependent Variable}

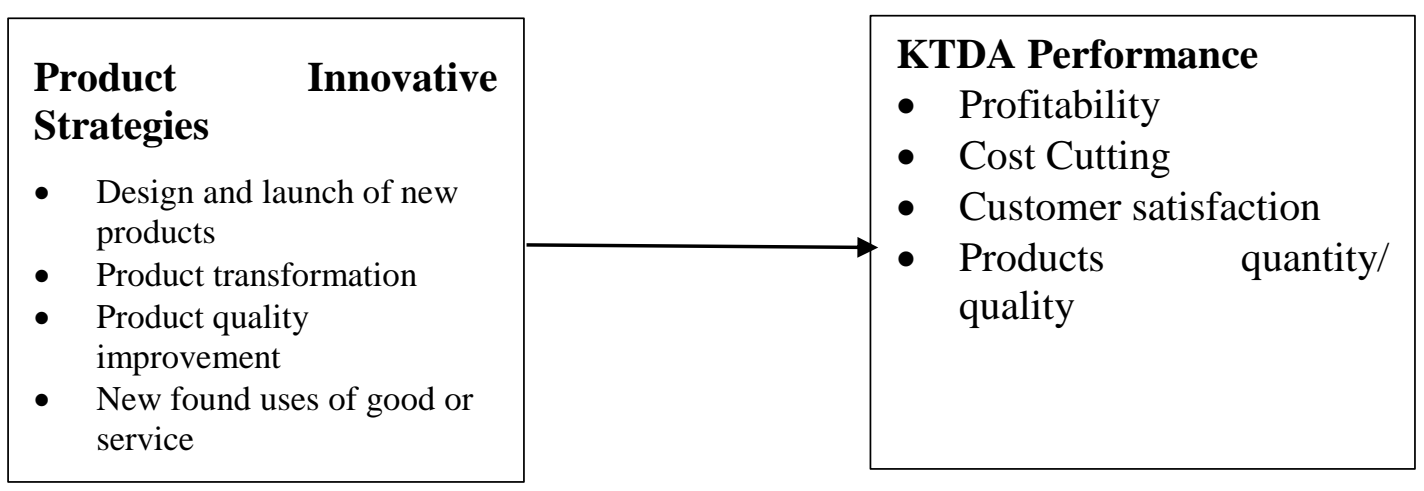

\section{Figure 1: Conceptual framework}

\section{Source: Adapted and modified from OECD, 2015}

\section{Research Methodology}

The study adopted correlational as well as cross-sectional survey research design, correlation is associated with not only testing the hypothesis but utilizing inferential statistics comprising of correlation analysis (Saunders, Lewis, \& Thornhill, 2011).

In this study the location of interest was KTDA factories in Kenya spread in 14 Counties. These consist of 71 factories. The target population was 974 employees from top level employees, middle level employees and lower level employees of KTDA managed factories. The main instrument of data collection was a semi- 
structured questionnaire administered to top, middle, and lower-level employees of KTDA factories in Kenya. The questionnaire was pre-tested to ensure its validity and reliability. An aggregate Cronbach Alpha coefficient of 0.703 was obtained which was above the threshold of 0.7. Data collected was screened, coded, entered, and analyzed using inferential statistics where multiple linear regression was employed to determine the significance of the hypothesis.

\section{Product Innovative Strategies and Performance of KTDA factories in Kenya}

There is no significant relationship between product innovative strategies and performance of Kenya Tea Development Agency Factories in Kenya.

This model was given as;

$\mathrm{Y}=\beta_{0}+\beta_{1} \mathrm{X}_{1}+\mathrm{e}$

$\mathrm{Y}=$ Performance, $\beta_{0}=$ Constant Term, $\beta_{1}=$ Beta coefficient, $\mathrm{X}_{1}=$ Product innovative strategies and $\varepsilon=$ Error term.

The results were presented in Table 1 .

Table 1: Product Innovative Strategies and Performance

\begin{tabular}{|c|c|c|c|c|c|c|c|}
\hline \multirow{2}{*}{\multicolumn{2}{|c|}{ Model }} & & \multicolumn{2}{|c|}{$\begin{array}{c}\text { Unstandardized } \\
\text { Coefficients }\end{array}$} & \multirow{2}{*}{$\begin{array}{c}\begin{array}{c}\text { Standardiz } \\
\text { ed } \\
\text { Coefficient } \\
\text { s }\end{array} \\
\text { Beta }\end{array}$} & \multirow[t]{2}{*}{$\mathbf{t}$} & \multirow[t]{2}{*}{ Sig. } \\
\hline & & $\mathbf{N}$ & Beta & $\begin{array}{c}\text { Std. } \\
\text { Error }\end{array}$ & & & \\
\hline & (Constant) & & 1.530 & .154 & & 9.944 & .000 \\
\hline & $\begin{array}{l}\text { Product Innovative } \\
\text { Strategies }\end{array}$ & $\begin{array}{c}28 \\
3\end{array}$ & .695 & .037 & .748 & 18.885 & .000 \\
\hline \multicolumn{8}{|c|}{$R=0.748$} \\
\hline \multicolumn{8}{|c|}{$R^{2}=0.599$} \\
\hline \multicolumn{8}{|c|}{$F=356.6$} \\
\hline \multicolumn{8}{|c|}{$P<0.05$} \\
\hline
\end{tabular}

\section{Source: Research Data (2022)}

The results from Table 1 shows a summary of the regression model fitness. The finding indicated that there existed a strong positive relationship between product innovative strategies and organizational performance $(\mathrm{R}=0.748)$. The $\mathrm{R}^{2}$ is the coefficient of determination which indicated that the explanatory power of independent variable was 0.599 . This means that a variation of $59.9 \%$ performance of KTDA was associated to product innovative strategies while other factors not captured by the model contributed the variance of $40.1 \%$.

The findings further, indicated that $\beta$ coefficient of 0.695 which implies that every unit increase of product innovative strategies contributes 0.695 increase in organizational performance. The results showed that the influence of product innovative strategies on performance of KTDA factories in Kenya was significant $(\mathrm{F}=356.6, \mathrm{p}<0.05)$. The null hypothesis that there is no significant relationship between product innovative strategies and performance of Kenya Tea Development Agency Factories in Kenya was rejected. This results concurs with Onikoyi (2017), who found that there existed positive and significant relationship between product innovative strategies and organizational performance. Similarly, Ar and Baki (2011), also found that product innovative strategies had positive and significant on organizational performance. Similarly, Oke, Prajogo and Jayaram (2013), pointed out that product innovative strategies affect the quality of performance of the product which affect significantly on the performance of the firm. Motero, Pennano and Camilo (2017), added that efficacy and efficiency was influenced by product innovative strategy. 


\section{Summary}

The objective was to establish the relationship between product innovative strategies and performance of Kenya Tea Development Agency Factories in Kenya. The findings revealed that KTDA factories were able to design and launch new tea product. The factories were able to monitor the latest tendencies in technology and adopt them in the product development. However, the factories were able to network with other organization in developing new product to some extent. Due to continuous research and development the factories were able to continuously adopt an innovative culture in product development. The factories were able to invest in capacity to meet scheduled initiatives and milestones while ensuring that business models were used to create products that target different market segments.

The result further indicated that product innovative strategies had positive significant relationship with the performance of KTDA factories in Kenya. Hence, product innovativeness strategies contribute to innovative strategies that impact on performance of the organization.

\section{Conclusions}

The study concluded that product innovative strategies had positive and significant relationship with performance of KTDA factories in Kenya. Product innovative strategies has contributed be the ability of the factory to design, launch tea products to different market segment, monitoring and adoption of latest trends in technology, continuous research and develop, innovative product culture and meeting factories schedules initiatives and milestones.

\section{Recommendations}

The study recommends that KTDA should adopt flexible business models that allow each factory to be autonomous in product development since there is room for improvement. This will allow the factory to introduce new products that can add value to the factory which will encourage continuous innovation of product culture. The flexibility of development of products with other institution will enable the factories to integrate products that are differentiated through value addition.

\section{Suggestion for Further Studies}

The study also suggests that since the research was limited in scope, a larger sample with a bigger population can be used for confirmatory analysis and validation.

\section{References}

1. Abeysinghe, I. (2013). Tea Research Institute Major Issues in the Tea Industry. India: Republic of India.

2. Ar, I., \& Baki, B. (2011). Antecedents and performance impacts of product versus process innovation. European Journal of Innovation Management, 3(2), 45-57.

3. Augusto, M., Lisboa, J., \& Yasin, M. (2014). Organisational performance and innovation in the context of a total quality management philosophy: An empirical investigation. Total Quality Management and Business Excellence, 25, 1144-1155.

4. Bao, Y., Chen, X., \& Zhou, K. (2012). External learning, market dynamics, and radical innovation: Evidence from China's high-tech firms. Journal of Business Research, 65(8), 1226-1233.

5. Baregheh, A., Rowley, J., \& Sambrook, S. (2009). Towards a multidisciplinary definition of innovation. Management Decision, 47(8), 1323-1339. doi:10.1108/002517409/0984578

6. Barney, J. B. 1986. Strategic factor markets: expectations, luck, and business strategy. Management Science, 32(10): 1231-1241.

7. Christian Partners Development Agency. (2008). Report on Small-Scale Tea Sector in Kenya. Nairobi, Kenya: CPDA.

8. Cozza, C., Malerba, F., Mancusi, M., Perani, G., \& Vezzulli, A. (2012). Innovation, profitability and growth in medium and high-tech manufacturing industries: evidence from Italy. Applied Economics, 44(15), 1963-1976.

9. Gunday, G., Ulusoy, G., Kilic, K., \& Alpkan, L. (2011). Effects of innovation types on firm performance. International Journal of Production Economics, 133(2), 662-676.

10. Hall, B. (2011). Journal of Supply Chain Management. Nairobi: National Bureau of Economic Research. 
11. Hernández-Espallardo, M., \& Delgado-Ballester, E. (2009). Product innovation in small manufacturers, market orientation and the industry's five competitive forces. European Journal of Innovation Management, 4(5), 122-134.

12. Im, S., \& J., W. (2004). Market orientation, creativity, and new product performance in hightechnology firms. Journal of Marketing, 68(2), 114-132.

13. International Finance Corporation. (2013). IFC's Investments. Kenya: Kenya Tea Development Agency Ltf.

14. Karanja, D. (2014). Effects of innovation strategies on performance of commercial banks in Kenya. University of Nairobi: Doctoral Dissertation.

15. Kirzner, I. M. 1997. Entrepreneurial discovery and the competitive market process: An Austrian approach. Journal of Economic Literature, 35(1): 60-85.

16. Letangule, S., Letting, D., \& Nicholas, K. (2012). Effect of innovation strategies on performance of firms in the telecommunication sector in Kenya. International Journal of Management \& Business Studies, 2(3), 75-78.

17. Levinthal, D. 1997. Adaptation on Rugged Landscapes. Management Science, 43(7): 934- 950.

18. Montero, R., Pennano, C., \& Camilo, L. (2017). Determinants of Product Innovation Performance: Why are some innovations more successful than others? Economia y Desarrollo, 158(2); 43-62.

19. Morton, J., 2020. On the susceptibility and vulnerability of agricultural value chains to COVID19. World development, 136, p.105132.

20. OECD. (2005). The measurement of scientific activities: Proposed guideline for collecting and interpreting technological innovation data. doi: dataoecd/35/61/2367580

21. Oke, A., Prajogo, D., \& Jayaram, J. (2013). Strengthening the innovation chain: The role of internal innovation climate and strategic relationships with supply chain partners. Journal of Supply Chain Management, 49(4), 43-58.

22. Onikoyi, I. (2017). Impact of Product Innovation on Organization Performance (A Survey of Nestle Nigeria Plc). Journal of Marketing and Consumer Research, 37, 24-31.

23. Polder, M., Leeuwen, V., Mohnen, P., \& Raymond, W. (2010). Product, process and organizational innovation: drivers, complementarity and productivity effects. Unumerit: Maastricht Economic and Social Research and Training Centre on Innovation and Technology.

24. Saunders, M., Lewis, P., \& Thornhill, A. (2011). Research Methods for Business Students 6th Ed. Harlow: Pearson.

25. Schumpeter, J. (1939). Business Cycles: A Theoretical, Historical and Statistical Analysis of the Capitalist Process. New York, NY: McGraw-Hill.

26. Shane, S. 2003. A General Theory of Entrepreneurship. The individual-opportunity Nexus. Massachusetts: Edward Elgar Publishing, Inc.

27. Therrien, P., Doloreux, D., \& Chamberlin, T. (2011). Innovation novelty and (commercial) performance in the service sector: A Canadian firm-level analysis. Technovation, 31(12), 655-665.

28. Utterback, J. M., \& Abernathy, W. J. (1975). "A dynamic model of product and process innovation", OMEGA. The International Journal of Management Science, 3(6), 639-656.

29. Wong, E., Ho, K., Wong, S., Cheung, A., \& Yeoh, E. (2020). Workplace safety and coronavirus disease (COVID-19) pandemic: Survey of employees. E-Pub: Bull World Health Organ. Retrieved March 20, 2020, from http://dx.doi.org/10.2471/BLT.20.255893 